\title{
BMUS guidelines for the regular quality assurance testing of ultrasound scanners by sonographers
}

\author{
Nick Dudley ${ }^{1}$, Stephen Russell ${ }^{2}$, Barry Ward ${ }^{3}$ and Peter Hoskins ${ }^{4}$; BMUS QA Working Party \\ ${ }^{1}$ Medical Physics Department, Lincoln County Hospital, Greetwell Road, Lincoln, UK \\ ${ }^{2}$ North Western Medical Physics Department, The Christie NHS Foundation Trust, Manchester, UK \\ ${ }^{3}$ Regional Medical Physics Department, The Freeman Hospital, Newcastle upon Tyne, UK \\ ${ }^{4}$ Medical Physics Department, University of Edinburgh, Edinburgh, UK \\ Corresponding author: Nick Dudley. Email: Nick.Dudley@ulh.nhs.uk
}

\begin{abstract}
Quality Assurance of ultrasound systems is necessary to ensure the reliability of results and to check for deterioration in performance; a number of bodies have produced guidelines. Testing has traditionally been the responsibility of Medical Physics Departments but the important role of sonographers has been recognised and recent publications have included tests to be performed by ultrasound users. Since there are differences in approach between these publications the BMUS QA Working Party was established to provide a consistent set of guidelines specifically for sonographers. Three levels of testing are recommended, to include infection control and inspections for scanner and probe damage, basic display checks and further tests to assess drop-out, sensitivity and noise. These tests should form part of a programme that includes more comprehensive testing at longer intervals, perhaps by a Medical Physics Department.
\end{abstract}

Keywords: Sonography, quality assurance

Ultrasound 2014; 22: 8-14. DOI: 10.1177/1742271X13511805

\section{Introduction}

The purpose of quality assurance (QA) of ultrasound systems is to ensure that consistent, reliable results are provided and to check for deterioration of equipment performance. A number of UK standard setting and professional bodies require or recommend QA and have produced publications relevant to ultrasound..$^{1-7}$

Traditionally, QA performance testing has been seen as the domain of the Medical Physics Department, involving extensive use of tissue mimicking phantoms (TMPs) and other test devices. Over time it has been recognised that sonographers have an essential role in the QA of ultrasound scanners.

The perceived importance of such tests has been somewhat eroded by the misconception that many of the issues they look for can readily be observed during routine scanning and appropriate action taken. Whilst this may have been the case several years ago, the level of processing applied to routine presets on an ultrasound scanner often masks such issues. It is therefore necessary to undertake tests where the minimum of image processing is applied and fundamental problems can then be readily observed.
QA guidelines have been produced by the IPEM (2010) ${ }^{7}$ the AIUM $(2008)^{8}$ and EFSUMB (2012), ${ }^{9}$ all of which involve tests performed by sonographers. However, the three organisations suggest slightly different approaches for sonographers' testing.

The purpose of these BMUS guidelines is to put in one place relevant guidelines for QA for sonographers including protocols, while at the same time trying to be consistent with the existing guidance above. Sonographer QA should be seen as part of a programme that includes more comprehensive testing at longer intervals, which may be provided by a Medical Physics Department. ${ }^{7,9}$ The guidelines have been trialled by sonographers in several centres, and their feedback incorporated into the final version.

\section{Guidelines}

These are guidelines for the performance of QA on ultrasound systems by sonographers. There are three levels of QA:

- Level 1. Infection control and scanner damage

- Level 2. Basic scanner and transducer testing

- Level 3. Further scanner and transducer testing 
Level 1 procedures have a two-fold purpose. The first is to ensure that the scanner is clean and that infection control risks to patients and staff are minimised. Secondly, checks are performed to detect any damage to the scanner, especially to the transducers and their cables. Infection control measures are relevant for every patient so that some of these actions are performed several times each day. Checks for scanner damage are performed weekly.

Level 2 procedures ensure appropriate setting of video monitor controls for consistency of imaging. They also provide a first-line evaluation of scanner performance but without the use of test tools or test objects. These tests are performed daily.

Level 3 procedures provide further evaluation of scanner performance using a very simple test tool. These checks are designed to look for scanner faults and are performed monthly.

Level 1 and 2 tests should form part of the ongoing activities of the sonographer and should not require dedicated time to be set aside, other than for simple documentation at the end of the day. Level 3 tests do require the sonographer to set aside dedicated time. Trialling of these guidelines suggest that this is no more than 15 minutes per week per scanner to perform the tests, document the results, undertake any follow-up action and return the scanner settings to their usual values.

The guidelines are contained in the tables below. These provide details of the task, the recommended frequency of performance of the task, relevant action levels and action to be taken in the event that a fault is detected. Details of protocols are provided in the appendix. Faults or results out of tolerance should be notified to the locally identified responsible person, for example the department manager or the Medical Physics Department, who will decide on further action according to local procedures, including any testing with TMP.

\section{Level 1. Infection control and scanner damage}

Weekly checks should be performed either before switching the scanner on or after switching it off.

\begin{tabular}{|c|c|c|c|}
\hline Identifier & Task & Frequency & $\begin{array}{l}\text { Comments/ } \\
\text { action }\end{array}$ \\
\hline 1.1 & $\begin{array}{l}\text { Clean ultrasound } \\
\text { gel and body } \\
\text { fluids from } \\
\text { scanner con- } \\
\text { sole, trans- } \\
\text { ducers and } \\
\text { cables after } \\
\text { every patient }\end{array}$ & Multi-daily & \\
\hline 1.2 & $\begin{array}{l}\text { Ensure trans- } \\
\text { ducers are } \\
\text { stored } \\
\text { securely when } \\
\text { not in use }\end{array}$ & Multi-daily & \\
\hline 1.3 & $\begin{array}{l}\text { Ensure trans- } \\
\text { ducer cables }\end{array}$ & Multi-daily & \\
\hline
\end{tabular}

Continued

\begin{tabular}{|c|c|c|c|}
\hline Identifier & Task & Frequency & $\begin{array}{l}\text { Comments/ } \\
\text { action }\end{array}$ \\
\hline & $\begin{array}{l}\text { are properly } \\
\text { stowed and } \\
\text { not at risk of } \\
\text { being run over } \\
\text { by the scanner } \\
\text { wheels }\end{array}$ & & \\
\hline 1.4 & $\begin{array}{c}\text { Clean monitors of } \\
\text { dust, gel, etc. }\end{array}$ & Daily & \\
\hline 1.5 & $\begin{array}{l}\text { Check the correct } \\
\text { operation of } \\
\text { the main scan- } \\
\text { ner controls }\end{array}$ & Daily & $\begin{array}{l}\text { If failure of oper- } \\
\text { ation inform } \\
\text { responsible } \\
\text { person }\end{array}$ \\
\hline 1.6 & $\begin{array}{l}\text { Inspect the trans- } \\
\text { ducers used } \\
\text { during the } \\
\text { session for } \\
\text { damage }\end{array}$ & Daily & $\begin{array}{l}\text { If suspected } \\
\text { damage } \\
\text { inform respon- } \\
\text { sible person. } \\
\text { For major } \\
\text { damage take } \\
\text { the transducer } \\
\text { out of service }\end{array}$ \\
\hline 1.7 & $\begin{array}{l}\text { Inspect switches, } \\
\text { knobs and } \\
\text { other controls } \\
\text { for damage }\end{array}$ & Weekly & $\begin{array}{l}\text { If suspected } \\
\text { damage } \\
\text { inform respon- } \\
\text { sible person }\end{array}$ \\
\hline 1.8 & $\begin{array}{l}\text { Inspect probe } \\
\text { cables, the } \\
\text { mains cable } \\
\text { and plug and } \\
\text { other cables, } \\
\text { e.g. network } \\
\text { and printer } \\
\text { cables, for } \\
\text { damage }\end{array}$ & Weekly & $\begin{array}{l}\text { If suspected } \\
\text { damage } \\
\text { inform respon- } \\
\text { sible person }\end{array}$ \\
\hline 1.9 & $\begin{array}{l}\text { Inspect the ultra- } \\
\text { sound system } \\
\text { for damage } \\
\text { such as cracks } \\
\text { and dents }\end{array}$ & Weekly & $\begin{array}{l}\text { If suspected } \\
\text { damage } \\
\text { inform respon- } \\
\text { sible person }\end{array}$ \\
\hline 1.10 & $\begin{array}{c}\text { Test of brake and } \\
\text { wheel function }\end{array}$ & Weekly & $\begin{array}{l}\text { If suspected } \\
\text { damage } \\
\text { inform respon- } \\
\text { sible person }\end{array}$ \\
\hline 1.11 & $\begin{array}{l}\text { Check air filters } \\
\text { for dust and } \\
\text { fluff }\end{array}$ & Weekly & Clean if dirty \\
\hline
\end{tabular}

Level 2. Basic scanner and transducer testing

\begin{tabular}{|c|c|c|c|}
\hline Identifier & Task & Frequency & $\begin{array}{l}\text { Comments/ } \\
\text { action }\end{array}$ \\
\hline 2.1 & $\begin{array}{l}\text { Check that the video } \\
\text { monitor's bright- } \\
\text { ness and contrast } \\
\text { controls have } \\
\text { been appropri- } \\
\text { ately adjusted }\end{array}$ & Daily & $\begin{array}{l}\text { If any deviation } \\
\text { from calibra- } \\
\text { tion points, } \\
\text { reset contrast } \\
\text { and brightness } \\
\text { to calibration } \\
\text { points }\end{array}$ \\
\hline
\end{tabular}


Ultrasound Volume 22 February 2014

Continued

\begin{tabular}{|c|c|c|c|}
\hline Identifier & Task & Frequency & $\begin{array}{l}\text { Comments/ } \\
\text { action }\end{array}$ \\
\hline 2.2 & $\begin{array}{l}\text { Check that the grey- } \\
\text { scale bar is fully } \\
\text { displayed }\end{array}$ & Daily & $\begin{array}{l}\text { If greyscale bar is } \\
\text { not fully dis- } \\
\text { played reset } \\
\text { contrast and } \\
\text { brightness } \\
\text { settings to new } \\
\text { calibration } \\
\text { points }\end{array}$ \\
\hline 2.3 & $\begin{array}{l}\text { Check grey levels on } \\
\text { the ultrasound } \\
\text { system monitor is } \\
\text { matched by grey } \\
\text { levels on PACS } \\
\text { system monitors }\end{array}$ & Daily & $\begin{array}{l}\text { If grey levels do } \\
\text { not match } \\
\text { adjust PACS } \\
\text { monitor } \\
\text { settings }\end{array}$ \\
\hline 2.4 & $\begin{array}{l}\text { Inspect reverberation } \\
\text { images for sha- } \\
\text { dows and streaks } \\
\text { caused by trans- } \\
\text { ducer dropout for } \\
\text { all transducers in } \\
\text { use that day }\end{array}$ & Daily & $\begin{array}{c}\text { Any suspicion of a } \\
\text { fault undertake } \\
\text { level } 3 \text { testing }\end{array}$ \\
\hline
\end{tabular}

\section{Level 3. Further scanner and transducer testing}

\begin{tabular}{|c|c|c|c|}
\hline Identifier & Task & Frequency & $\begin{array}{l}\text { Comments/ } \\
\text { action }\end{array}$ \\
\hline 3.1 & $\begin{array}{l}\text { Air reverberation } \\
\text { pattern } \\
\text { (sensitivity) }\end{array}$ & Monthly & \multirow{3}{*}{$\begin{array}{l}\text { If out of tolerance } \\
\text { contact } \\
\text { responsible } \\
\text { person. If } \\
\text { system is to } \\
\text { continue in use } \\
\text { ensure a } \\
\text { documented } \\
\text { contemporary } \\
\text { clinical } \\
\text { assessment is } \\
\text { performed }\end{array}$} \\
\hline 3.2 & $\begin{array}{l}\text { Element dropout } \\
\text { test }\end{array}$ & $\begin{array}{l}\text { If fault in } 2.4 \text {. } \\
\text { Monthly for } \\
\text { phased } \\
\text { arrays }\end{array}$ & \\
\hline 3.3 & $\begin{array}{l}\text { Electronic noise } \\
\text { assessment } \\
\text { (B-mode, } \\
\text { Doppler and } \\
\text { Colour Flow) }\end{array}$ & Monthly & \\
\hline 3.4 & $\begin{array}{c}\text { Date of electrical } \\
\text { safety testing }\end{array}$ & Monthly & $\begin{array}{l}\text { If electrical safety } \\
\text { testing is due } \\
\text { within one } \\
\text { month, or } \\
\text { overdue, } \\
\text { inform the } \\
\text { responsible } \\
\text { person }\end{array}$ \\
\hline
\end{tabular}

\section{DECLARATIONS}

Competing interests: The authors have no conflicts of interest to declare.

Funding: This research received no specific grant from any funding agency in the public, commercial, or not-for-profit sectors.

Ethical approval: No ethical approval was required.
Guarantor: NJD

Contributorship: PH chaired the Working Party. All authors contributed to the development of the guidelines and reviewed the final draft.

\section{REFERENCES}

1. Department of Health (DoH). Diagnostic Tests - Direct Access Non-Obstetric Ultrasound Service. London: DoH, 2013

2. CQC National Standards. See http://www.cqc.org.uk/public/what-arestandards/national-standards (last checked 18 February 2013)

3. National Health Service Litigation Authority (NHSLA). NHSLA Risk Management Standards 2012-2013. London: NHSLA, 2012

4. Medical and Healthcare products Regulatory Authority (MHRA). Devices in Practice: A Guide for Professionals in Health and Social Care. London: MHRA, 2008

5. United Kingdom Association of Sonographers (UKAS). Guidelines for Professional Working Standards: Ultrasound Practice. London: UKAS, 2008

6. Royal College of Radiologists (RCR). Standards for Ultrasound Equipment. London: RCR, 2005

7. Institute of Physics and Engineering in Medicine (IPEM). Quality Assurance of Ultrasound Imaging Systems. York: IPEM, 2010

8. American Institute of Ultrasound in Medicine (AIUM). Routine Quality Assurance for Diagnostic Ultrasound Equipment. Laurel, USA: AIUM, 2008

9. Kollman C, deKorte C, Dudley NJ, et al. Guideline for technical quality assurance (TQA) of ultrasound devices (B-Mode) - version 1.0 (July 2012). Ultraschall Med 2012;33:544-9

\section{Appendix 1. Protocols Level 1}

1.1. Cleaning of cables and transducers. Transducers should be wiped gently with a non-textured paper towel, taking care not to cause wear to the lens. Use of a manufacturer-recommended cleaning agent is acceptable. Avoid use of alcohol, such as alcohol wipes, as these can damage the transducer.

1.2. Transducer storage. Transducers should be stored in their holder, usually on the side of the ultrasound scanner, when not in use. Avoid leaving the transducer on other surfaces such as the patient couch as they can fall off and be damaged.

1.3. Care of transducer cables. For transducers not in use, the cables should be correctly stowed so that they do not trail on the ground. For transducers in use, some of the cables may trail on the ground; in these circumstances care should be taken when moving the scanner or chair to avoid running over the cable as this is a potential cause of damage.

1.4. Cleaning of monitors. Clean dust from the monitor gently with a soft dry cloth. Stains can be removed by using a moist (not wet) soft cloth. A manufacturer-approved screen cleaner is also acceptable. Avoid paper towels as these can scratch the screen. Avoid ammonia-based products as these can damage flat screen LCD monitors. 
1.5. Checking of main scanner controls. Check that the most used controls are functioning normally, and that there are no faults such as controls which fail to respond or stick, or respond intermittently.

1.6. Inspection of transducers. Visually inspect all transducers for signs of wear and damage. The transducer generally consists of a hard plastic casing bonded to a lens for the active scanning face. The lens may be hard but is more often a softer material and is prone to splits/cuts, abrasive wear, lifting and bubbling. Attention needs to be paid to the edge of the lens where it is bonded to the plastic casing. Applying a light pressure to the probe at the junction between the lens and plastic casing may reveal movement suggesting damage to the bonding. Abrasive wear may show itself as either a dulling or shining or change in texture of the lens and is most common at one or more of the corners, sometimes demonstrating complete wearing of the lens allowing ultrasound elements to be seen. The hard plastic casing needs to be inspected for hairline cracks. It is noted that incorrect use of cleaning agents can result in the casing becoming brittle, making it prone to stress fractures; they may also react with the lens material indicated by colour or surface texture changes. Minor damage should be noted and the responsible person informed. Major damage should result in the probe being taken out of service for further inspection and potentially replacement or repair. All instances where the integrity is compromised, such that gel or water may ingress, should be treated as major and the probe subjected to electrical safety tests as an applied part.

1.7. Inspection for damage to controls. Visually inspect the controls for signs of wear or abrasion. Non-sealed knobs should be inspected for ingress of scanning gel.

1.8. Inspection of cables. This should be performed with the scanner switched off. Inspect the probe cables, mains cables, plugs and cables to any attached peripherals for damage. Running the cable carefully through your hand, gently pinching the cable between the thumb, first and second finger will reveal any cuts, abrasions, twisting or deformation or stress internal to the cable. It can also be useful to examine the outer sleeves, looking for a change in shade or colour. Disconnect the probes (never do this with the probe operating) and check the connectors for physical damage and signs of stress (e.g. twisted or misaligned pins, abrasion or corrosion for surface connections). Damage should be noted and the responsible person informed.

1.9. Inspection of the console and main body of the scanner. Visually inspect the ultrasound system for bumps and dents which may have been caused during transport of the scanner, or from other equipment crashing into the scanner, or in the case of portable or trolley-based equipment from being dropped. Also check the movement and locking mechanism of any moving parts, e.g. video monitor, console and keyboard. Faults or damage should be noted and the responsible person informed.

1.10. Brake and wheel function. If the scanner is used in a single location, then check it for stability (namely that the brakes are holding it securely). If the scanner is moved to various locations then unlock the brakes and check the system for smooth movement ensuring that there is no pull or drag and that one pair of wheels can be locked in position for ease of steering; then re-engage the brakes at the working position and check the system for stability. Damage should be noted and the responsible person informed.

1.11. Air filters. Check the filters (often located towards the bottom of the scanner body) for dust and fluff, which could allow damaging heating to occur. If dirty, gently clean the filters with a cloth, brush or vacuum cleaner, depending on manufacturers' recommendations.

\section{Level 2}

2.1. Video monitor brightness and contrast adjustment. If brightness and contrast controls have been altered from their baseline settings, readjust to those recorded or marked on the display. If the scanner is used in more than one location, it is possible that slightly different settings may be required in each.

2.2. Greyscale bar. The monitor should be viewed and adjusted in the same lighting conditions as scanning is performed; ideally lighting should be subdued with no bright light sources or reflections (this also applies to all subsequent tests where the monitor is viewed). The greyscale bar should show peak white at one end and the darkest grey scale at the other (the latter can be checked by increasing brightness to see if further grey steps appear). The monitor background should be black (only just). There should be a continuous gradient from white to black. If this is not the case, adjust the contrast and brightness to achieve this and record the new values as baseline for future reference.

2.3. Greyscale compatibility with PACS monitors. The greyscale bar on ultrasound images displayed on PACS monitors should be as described above. Any differences may be due to PACS set up and should be discussed with the system administrator.

2.4. Visual inspection of images. This test is not possible on phased array probes. Turn off harmonic, 
trapezoidal and compound imaging, as these may mask faults. With the probe operating in air and free of gel, inspect the reverberation pattern for axial banding (dropout), which would indicate a failure of the element, cable, connector or transmit/receive channel. Note that on many probes subtle non-uniformity is normal. If there is any suspicion of a fault, perform Level 3 testing and report to the responsible person. Reference images may be stored to the local hard drive or to PACS to assist with the observation of change. Note that any shadows or streaks arising from the proximal part of clinical images are likely to represent a more serious fault and should be immediately reported to the responsible person.

\section{Level 3}

3.1. Air reverberation pattern (sensitivity). Operate the transducer dry in air. Use settings recorded at baseline, as described below, i.e. select appropriate preset; select a fundamental frequency (not harmonic); alter output to $100 \%$; increase the overall gain to maximum and ensure Time Gain Compensation (TGC) sliders are positioned centrally (or as set at baseline); move a single focus to the most superficial setting; turn off compounding, trapezoidal imaging and realtime adaptive image processing, e.g. XRes and Precision. A reverberation pattern should be seen consisting of a series of lines parallel to the transducer face. There may be some symmetric structure to the pattern as a result of the beam-former operation. Any local change in the reverberation pattern may indicate dropout. Adjust the scale so that the full face of the transducer is in the image and if possible such that the reverberations occupy at least $25 \%$ of the image depth (more care is needed for linear transducers). Measure and record the distance from the top of the image to the deepest visible reverberation in the centre of the image, as shown in Figure 1. Record the image and note and report any changes to images recorded at baseline.

3.2. Element dropout test. This test should be performed if dropout is suspected in 2.4 or 3.1 above. With settings as for 3.1 run the smooth edge of a paperclip along the probe (for hard lenses a smear of water may be needed to improve coupling). The paperclip will produce strong echoes localised at the point of contact (Figure 2(a)). Any loss of echoes (Figure 2(b)) indicates element dropout, which is likely to be clinically significant. Any abnormal findings should be reported to the responsible person.

3.3. Electronic noise assessment. Using the settings for the above measurements, reduce the overall gain to the point where noise has just disappeared from the image (Figure 3; normally disappears last at the bottom of the image) and record the gain value as the noise threshold. Note and report any change from the baseline. Note that it can occasionally be helpful to reduce superficial TGC to eliminate bright reverberation lines. If noise is not seen at the depth setting used in 3.1 this test may be performed at a greater depth as long as this is recorded as the standard setting. Pulsed

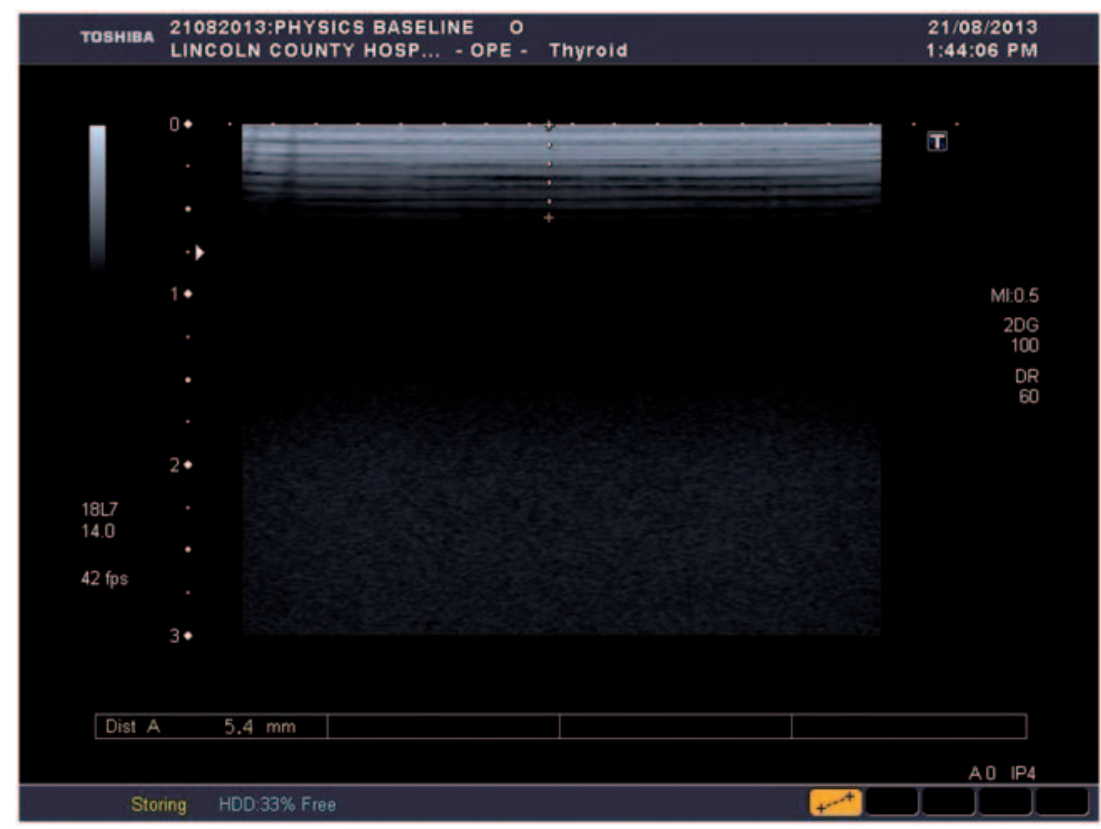

Figure 1 Air reverberation pattern (sensitivity) measurement, from the top of the image to the deepest visible reverberation line 

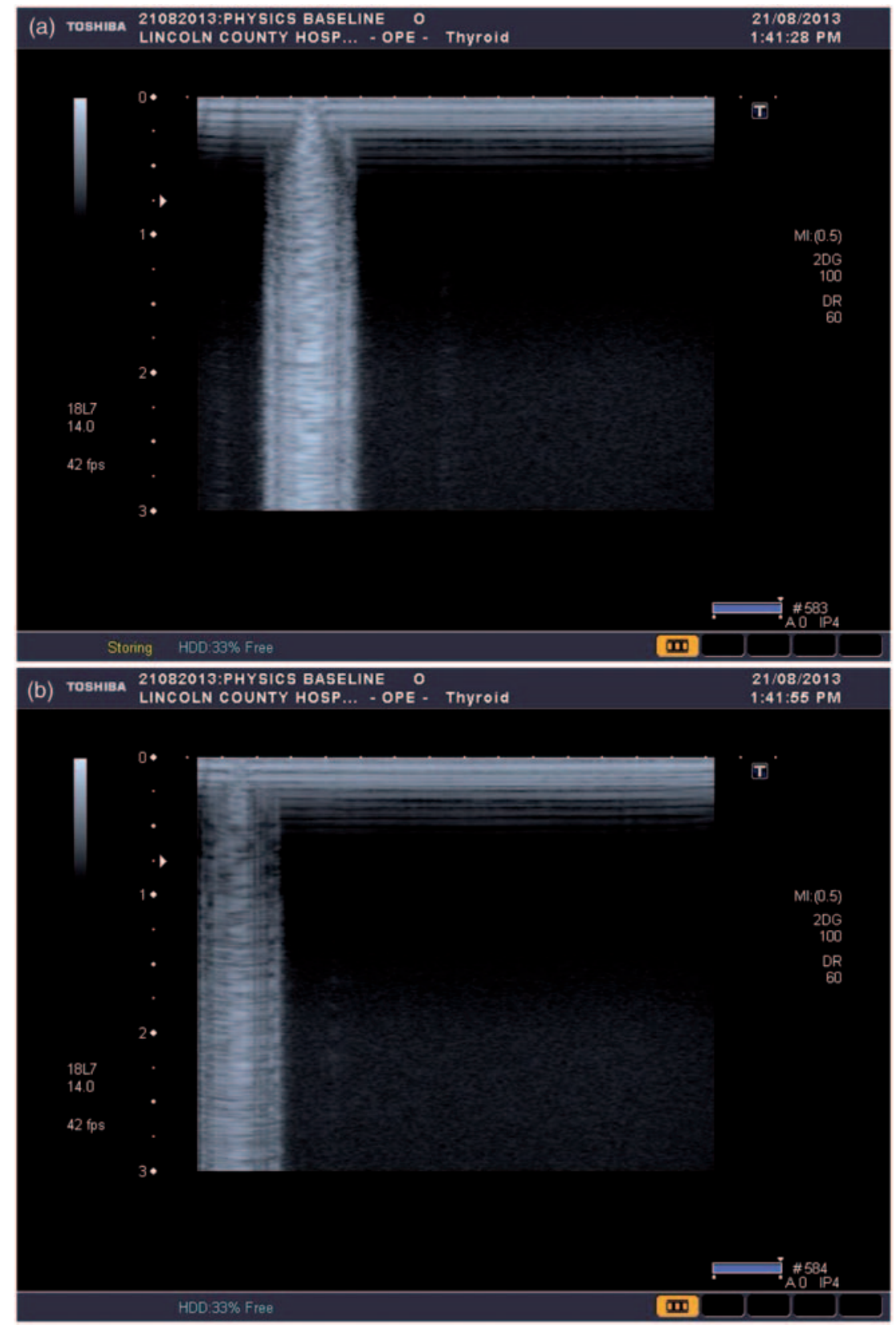

Figure 2 (a) Normal paperclip reverberation pattern; (b) reduced paperclip reverberation brightness in dropout region

Wave (PW) Doppler and Colour Flow Imaging (CFI) may be tested in the same way; for PW select the recorded frequency, move the range gate to the centre of the image and reduce gain until noise just disappears; for CFI select the recorded frequency, move the colour box to the bottom centre of the image and reduce gain until noise just disappears.

3.4. Date of electrical safety testing. Check the date that electrical safety testing is next due (there should be a sticker on the scanner body, or an entry in the service record). If this is due within the next month, or overdue, inform the responsible person who should arrange for testing.

\section{Baselines and tolerances for Level 3}

In organisations with Medical Physics or Clinical Engineering Departments, there will probably be staff with the expertise to set baselines and provide more comprehensive testing and advice.

Operate the transducer dry in air. Select a commonly used preset, using a factory version where possible (as this is less likely to be changed). Select a fundamental frequency, i.e. not harmonic. Alter output to maximum. Increase the overall gain to maximum and ensure TGC sliders are positioned centrally (unless there is no central click, when they should be set to maximum). Move a single focus to the most superficial setting. Turn off compounding, trapezoidal imaging and any real-time adaptive image 


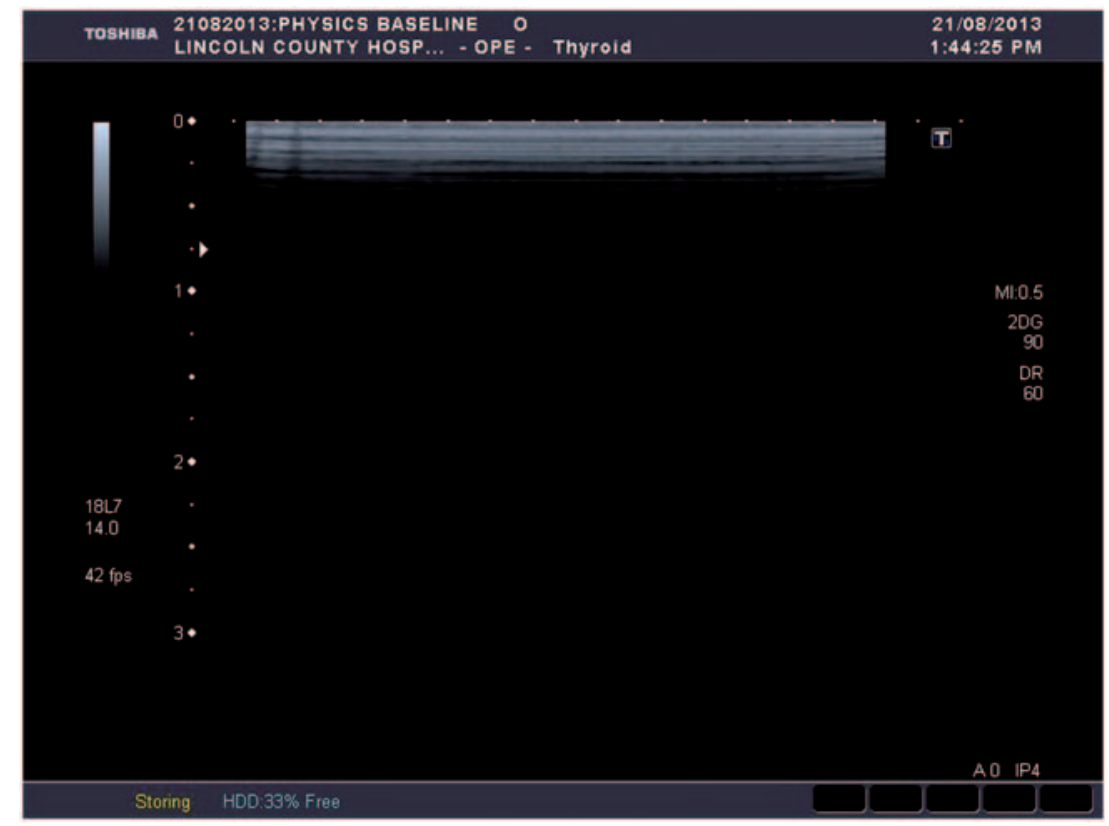

Figure 3 Electronic noise assessment. The gain has been reduced to the point where noise has disappeared (2DG 90 in the image; at gain of 91 noise becomes visible)

processing. A reverberation pattern should be seen consisting of a series of lines parallel to the transducer face. There may be some symmetric structure to the pattern as a result of the beam-former operation. Any local change in the reverberation pattern may indicate element dropout. Adjust the scale so that the reverberations occupy at least $25 \%$ of the image depth, with the full face of the transducer in the image. Measure and record the distance from the top of the image to the deepest visible reverberation in the centre of the image. Record the image. Record the result as the baseline for the air reverberation pattern test and record \pm the distance to the adjacent reverberation line as the tolerance. Note the preset, frequency and all adjustments made, to allow the test to be repeated reproducibly.

Note that for phased array probes a clear reverberation pattern will not be seen. Reverberation echoes will be seen as a haze and great care is required in determining the measurement point and tolerances.
Using the settings for the above measurement, reduce the overall gain to the point where noise has just disappeared from the image (normally disappears last at the bottom of the image) and record this as the noise threshold. The tolerance must be subjectively set and may be determined by repeating the measurement and establishing a range of likely results, which may be modified after gaining experience performing the test routinely. Note that it can be helpful to reduce superficial TGC to eliminate bright reverberation lines. If noise is not seen at the depth setting used above, this test may be performed at a greater depth as long as this is recorded as the standard setting.

PW Doppler and CFI may be tested in the same way; for PW record the default frequency, move the range gate to the centre of the image and reduce gain until noise just disappears; for CFI record the default frequency, move the colour box to the bottom centre of the image and reduce gain until noise just disappears. 